\title{
34. INVESTIGATIONS OF TERTIARY CLAY MINERAL DISTRIBUTIONS AROUND TASMANIA, DSDP, LEG 29
}

\author{
Victor A. Gostin, Department of Geology, University of Adelaide, South Australia \\ and \\ Kevin C. Moriarty, Discipline of Earth Sciences, Flinders University of South Australia
}

\begin{abstract}
Clay minerals from Tertiary samples of DSDP Sites 280, 281, 282, and 283 were analyzed mainly by X-ray diffraction and cation exchange methods. Site 282 , off the Tasmanian west coast, contains a persistent Australian clay mineral assemblage that reflects deep weathering conditions in Tasmania and basic volcanism increasing from Eocene into the Oligocene. Site 280, south of the South Tasman Rise, was probably situated close to Antarctica in the EoceneOligocene and shows a change from temperate source area conditions in the early(?) and middle Eocene, to cold-glacial conditions in the latest Eocene and Oligocene. This is supported by OligoceneMiocene data from cores near Antarctica.

It is unlikely that any deep oceanic connection existed between the basins on either side of the South Tasman Rise until probably the late Oligocene when the circum-Antarctic current developed.
\end{abstract}

\section{INTRODUCTION}

This investigation forms part of a larger study involving the detailed clay mineralogy of Recent and Tertiary sediments in the Southern Ocean between Australia, New Zealand, and Antarctica. It concentrates on the clay minerals of the Tertiary sequences in the Leg 29 DSDP sites that surround Tasmania (Sites 280 to 283). For significant interpretations it is obviously necessary to compare these results with those obtained from sites of DSDP Leg 28, south of New Zealand and in the Australian region of Antarctica.

Among other factors, clay mineral types and proportions are influenced by the nature of the source rocks and their degree of weathering. The $<2-\mu$ fraction in the ocean should become relatively dispersed within any depositional area and therefore should show the integrated effect of its provenance and conditions of weathering. As a consequence, clay mineral proportions may be used to outline certain provinces that have characteristic clay mineral distributions. Such analyses may be usefully compared to proposed paleoclimatic and plate tectonic hypotheses.

The clay mineral results obtained are shown in Table 1 and illustrated on Figure 1. Results from DSDP X-ray analyses (Appendix I, this volume) are shown in Figure 2. The vertical scale on the figures is a direct time scale, and lithologic columns are shown for each site. The drilling sites in the figures are arranged in such a way that Site 281 on the South Tasman Rise separates Site 282 in the ocean basin west of Tasmania, from Sites 280 and 283 which are to the east or south of the rise. If, as is proposed, the separation of Australia and Antarctic occurred along a set of transform faults that extend south from along the west coast of Tasmania, then this arrangement is appropriate for mineral analyses around the area of final separation, i.e., the South Tasman Rise.

Since widely different results may be obtained by using differing analytical methods, details of the methods used here are described.

\section{ANALYTICAL METHODS}

The samples were washed free of salts. A subsample was used to determine bulk chemical composition by Xray fluorescence (XRF) spectroscopy. The sand fraction was removed by wet seiving in a $63 \mu$ sieve. Carbonate was removed from the $<63 \mu$ fraction by glacial acetic acid. The $<2 \mu$ fraction was separated by repeated centrifugation, and clay/silt proportions obtained by weighing the fractions after washing in alcohol, acetone, and ether, and air drying. Amorphous silica was removed from the $<2 \mu$ fraction following the method of Hashimoto and Jackson (1960). The solute was saved for analysis of $\mathrm{Si}$ and $\mathrm{Al}$ content in order to test for clay mineral dissolution. Amorphous iron is removed following the method of Mehra and Jackson (1960) and the solute saved for analysis of $\mathrm{Fe}, \mathrm{Al}$, and $\mathrm{Si}$. A known amount of clay is sedimented onto corundum tiles over a vacuum saturated with $\mathrm{Mg}$, glycerine, and air dried. Xray diffraction is carried out in the range of $3^{\circ}$ to $26^{\circ}$, with variations for particular samples. A separate sample is sedimented onto a corundum disc over a vacuum. The disc is saturated with $2 \mathrm{~N} \mathrm{BaCl}_{2}$, washed, dried, and analyzed for $\mathrm{Ba}, \mathrm{K}$, and chlorine content by XRF. The barium content is used to calculate the cation exchange capacity.

The aim of these preparation procedures is to obtain a sediment fraction in which the component minerals are readily identifiable and their relative quantities determinable. It is expected that an amount (usually low) of 
TABLE 1

Clay Mineral Ratios as Determined by X-Ray Diffraction and by Cation Exchange Methods

\begin{tabular}{|c|c|c|c|c|c|c|c|c|}
\hline \multirow{2}{*}{$\begin{array}{c}\text { Sample } \\
\text { (Interval in } \mathrm{cm} \text { ) }\end{array}$} & \multicolumn{2}{|c|}{ Chlorite } & \multicolumn{2}{|c|}{ Kaolinite } & \multicolumn{2}{|c|}{$\begin{array}{l}\text { Montmor- } \\
\text { illonite }\end{array}$} & \multicolumn{2}{|c|}{$\begin{array}{c}\text { Illite } \\
\text { Muscovite }\end{array}$} \\
\hline & XRD & CEC & XRD & CEC & XRD & CEC & XRD & CEC \\
\hline $280-1-3,122$ & 46.8 & 47.9 & 0 & 0 & 3.9 & 1.7 & 49.3 & 50.4 \\
\hline $280 \mathrm{~A}-1-3,122$ & 19.7 & 21.4 & 2.5 & 2.8 & 34.4 & 28.7 & 43.4 & 47.2 \\
\hline $280 A-4-4,96$ & 27.7 & 22.2 & 2.1 & 1.7 & .9 .4 & 27.4 & 60.8 & 48.7 \\
\hline $280 \mathrm{~A}-6-2,97$ & 47.9 & 45.8 & 0 & 0 & 2.6 & 6.8 & 49.5 & 47.4 \\
\hline $280 A-8-2,105$ & 38.2 & 34.0 & 0 & 0 & 13.6 & 23.1 & 48.2 & 42.9 \\
\hline $280 \mathrm{~A}-11-2,70$ & 25.8 & 22.8 & 8.7 & 7.7 & 6.1 & 17.1 & 59.4 & 52.4 \\
\hline $280 \mathrm{~A}-13-2,109$ & 7.2 & 25.3 & 0.5 & 1.7 & 77.8 & 22.3 & 14.5 & 50.7 \\
\hline $280 \mathrm{~A}-15-2,34$ & 12.6 & 25.1 & 0 & 0 & 52.6 & 5.9 & 34.8 & 69.0 \\
\hline $280 \mathrm{~A}-17-6,54$ & 5.4 & 14.9 & 0 & 0 & 80.4 & 46.3 & 14.2 & 38.8 \\
\hline $280 A-19-5,54$ & 8.3 & 26.5 & 0 & 0 & 79.2 & 33.6 & 12.5 & 39.8 \\
\hline $280 \mathrm{~A}-20-2$ & 13.7 & 30.0 & 0 & 0 & 58.9 & 10.0 & 27.4 & 60.0 \\
\hline $280 \mathrm{~A}-22-1,91$ & 0 & 0 & 9.6 & 15.2 & 36.5 & 0 & 53.9 & 85.2 \\
\hline $281-6-5,70$ & 16.5 & & 23.2 & & 13.0 & & 47.3 & \\
\hline & 19.5 & & 5.4 & & 13.4 & & 61.7 & \\
\hline$-4,10$ & 12.7 & & 0.3 & & 4.7 & & 82.3 & \\
\hline-13, CC (top) & 0 & & 0.4 & 0.4 & 0 & & 99.6 & 99.6 \\
\hline$-14-6,110$ & 16.6 & & 22.4 & & 20.3 & & 40.7 & \\
\hline $15-3,60$ & 18.5 & 17.2 & 13.6 & 12.6 & 35.5 & 40.1 & 32.4 & 30.1 \\
\hline & 12.8 & & 15.7 & & 33.0 & & 38.5 & \\
\hline & tr & 0 & 39.0 & 39.3 & 15.9 & 15.2 & 45.1 & 45.5 \\
\hline & tr & 0 & 39.6 & 46.3 & & 40.9 & & 12.9 \\
\hline & $\operatorname{tr}$ & 0 & 25.2 & 30.2 & 64.1 & 56.9 & 10.7 & 12.5 \\
\hline $1-3,85$ & $\operatorname{tr}$ & 0 & 41.5 & 32.0 & 47.4 & 59.5 & 11.1 & 8. \\
\hline $3-2,89$ & 12.8 & 11.4 & 36.0 & 32.1 & 28.4 & 36.3 & 22.8 & 20.2 \\
\hline $282-14-3,83$ & tr & 0 & 51.8 & 62.0 & 32.9 & 19.7 & 15.3 & 18.3 \\
\hline $282-16$, CC & 0 & 0 & 67.8 & 54.1 & 22.0 & 37.8 & 10.2 & 8. \\
\hline & 0 & 0 & 57.8 & 61.6 & & 24.8 & 12.8 & 13. \\
\hline $8-1109$ & 0 & 0 & 33.7 & 56.1 & 55.3 & 25.4 & 11.0 & 18.4 \\
\hline & 16.6 & 30.9 & 13.9 & 26.0 & 56.3 & 18.3 & 13.2 & 24.8 \\
\hline & 5.4 & & 4.3 & & 77.8 & & 12.5 & \\
\hline $283-13-2,81$ & 0 & 0 & 0.6 & 7.8 & 93.8 & 21.5 & 5.6 & 70.7 \\
\hline $283-17-4,94$ & 24.6 & 22.4 & 3.9 & 3.6 & 41.9 & 47.0 & 29.6 & 27.0 \\
\hline
\end{tabular}

the clay minerals is removed by these treatments, and the removal will be a differential process according to the size and nature of the mineral particles. To minimize this effect, all samples were subjected to exactly the same treatments. The clay mineral groups, kaolinite, illitemuscovite, montmorillonite, and chlorite, constitute the bulk of the $<2 \mu$ fraction in all cases and are affected very little by the treatments. Zeolites are removed by the treatments, allowing quantification of the montmorillonite by cation exchange methods.

\section{MINERAL IDENTIFICATION AND QUANTIFICATION}

Montmorillonite was determined both by the height of the $17 \AA$ peak obtained after glycerine saturation and from the cation exchange capacity (CEC). In the calculations it is assumed that the CEC of montmorillonite is $100 \mathrm{meq} / 100 \mathrm{~g}$. This has been shown to be reasonable by analysis of nearly pure montmorillonite from the surface sediments in the area.

Chlorite was determined from the height of the $14 \AA$ (001) peak, with the presence of a (003) peak at $4.72 \AA$ to confirm the abundance. There are various methods to determine the relative contributions of kaolinite and chlorite to the $7 \AA$ peak. Those of Biscaye (1964) and
Schultz (1960) were applied without consistent success and were thus not used any further. A refinement of the method of Rex and Murray (1970) and Pow-foong Fan and Rex (1972) was used. This assumes a constant ratio of the (001), (002), and (003) peak heights for the deepsea chlorites. The height of the $(003)$ reflection is used to determine the relative abundance of chlorite, and the contribution of this chlorite to the $7 \AA$ peak is calculated from a constant ratio. Since the (001) and (003) reflections of chlorite are very sensitive to the variations in iron content and position in the lattice, any variation in the composition of the chlorites will give a misleading abundance. This will especially affect the kaolinite quantification. Accordingly, this study tried to determine the possible variations in chlorite composition at Site 280 by measuring ratios of the $(001 / 002 / 003)$ reflections.

The results, shown in Table 2, indicate that the ratios vary in a way that cannot be explained by variation in the kaolinite proportion. Sample 280-1-3 contains negligible kaolinite, and the $(001 / 002)$ ratio is 2.1 . The average ratio for all other samples with high chlorite content is 0.83 . These results are consistent with those obtained from Mg-chlorites. The variation in (001/003) ratios shows that the assumption of constant composi- 

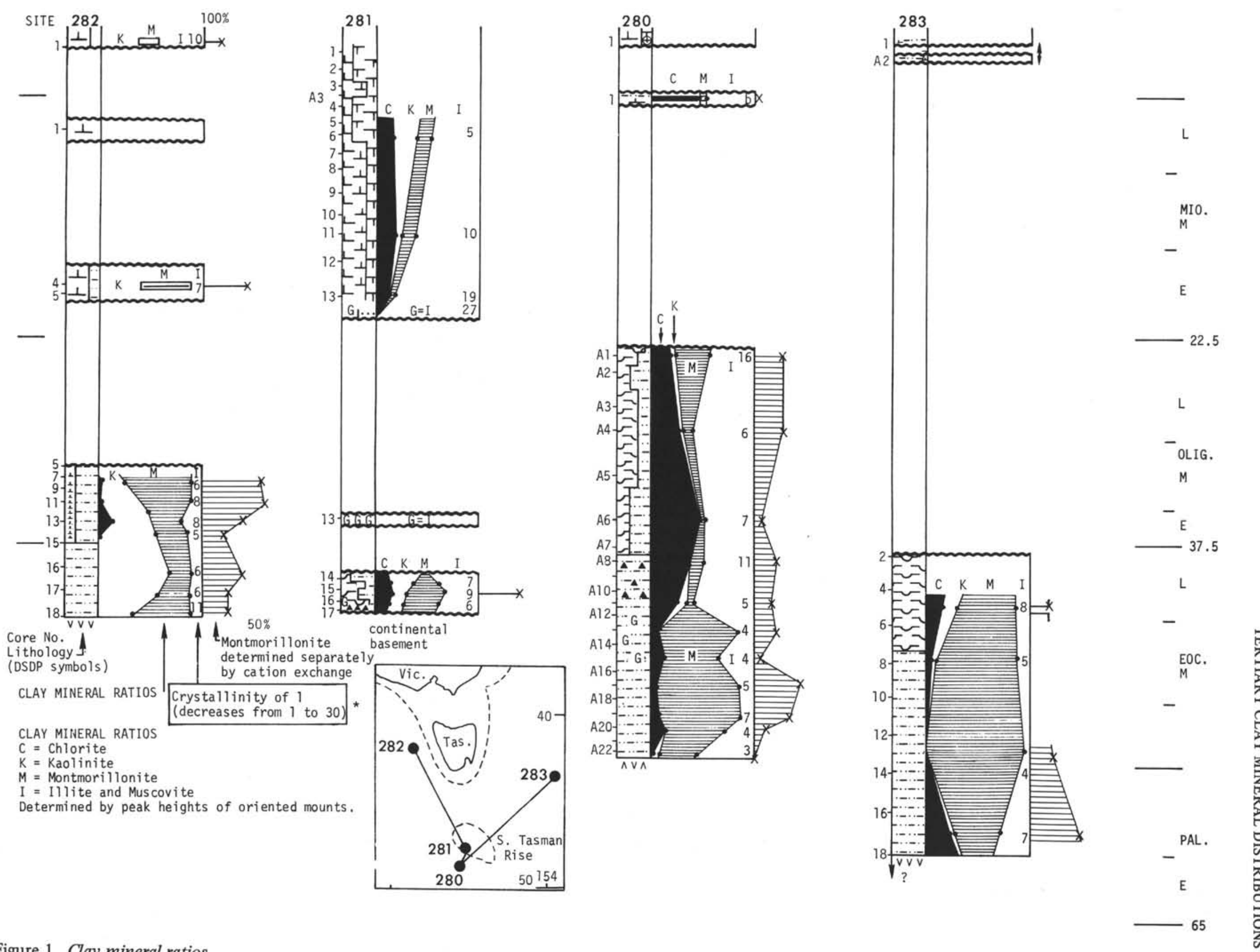

Figure 1. Clay mineral ratios. 


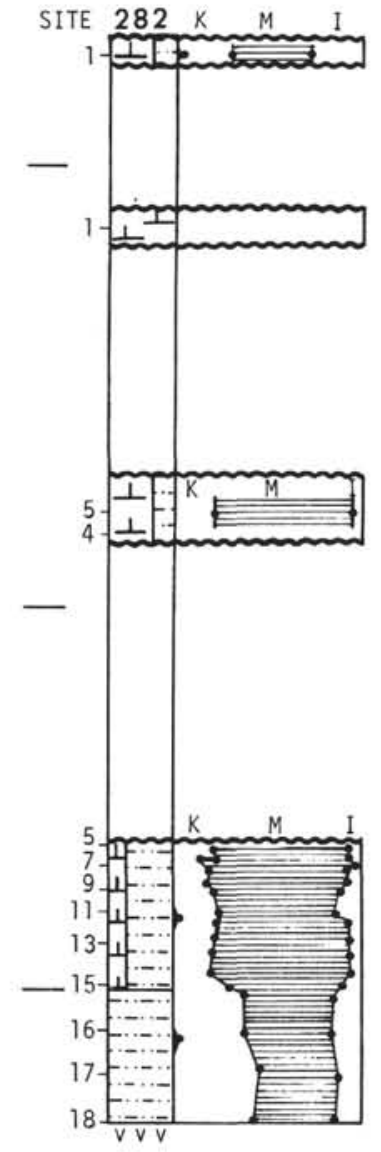

Clay minerals determined as random powders on decalcified, $<2$ Im fraction.

Clay minerals arranged in

$C=C h l o r i t e, K=K a o l i n i t e, M=M o n$ tmorillonite,

MIXL=Mixed layer mica-montmorillonite.

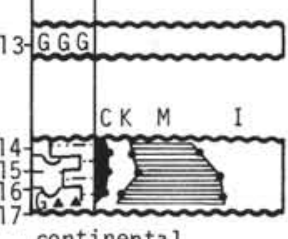

continental

(n)
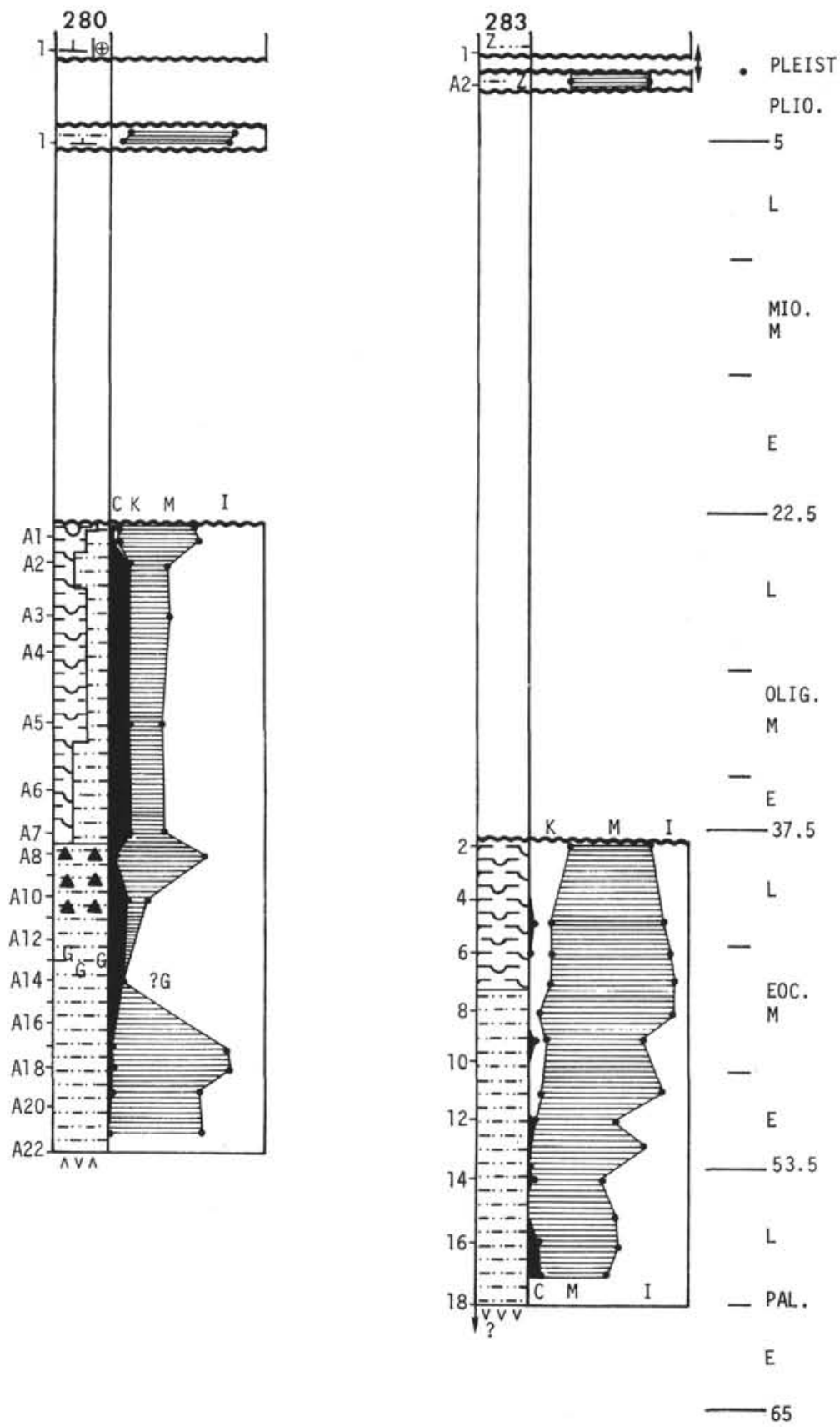
TABLE 2

ool Ratios for High Chlorite

Samples, Site 280

\begin{tabular}{lcc}
\hline \multicolumn{1}{c}{ Sample } & $001 / 002$ & $001 / 003$ \\
\hline $280-1-3$ & 2.1 & 4.9 \\
$280 \mathrm{~A}-1-3$ & 0.7 & 3.4 \\
$280 \mathrm{~A}-4-4$ & 0.7 & 2.5 \\
$280 \mathrm{~A}-6-2$ & 1.0 & 3.8 \\
$280 \mathrm{~A}-8-2$ & 1.1 & 4.8 \\
$280 \mathrm{~A}-11-2$ & 0.5 & 1.8 \\
$280 \mathrm{~A}-13-2$ & 0.8 & 3.0 \\
$280 \mathrm{~A}-15-2$ & 0.9 & 3.0 \\
$280 \mathrm{~A}-17-6$ & 0.9 & 4.0 \\
\hline
\end{tabular}

tion is not justified. However, it is assumed that all samples had a $(001 / 002)$ ratio of $\geq 0.83$ for the chlorite. If the ratio in any particular sample was higher, then all of the $7 \AA$ peak was attributed to chlorite. If the ratio was less than 0.83 , the $7 \AA$ peak height was divided proportionately between kaolinite and chlorite. Taking a higher ratio than 0.83 may be justified from the evidence, thereby raising the kaolinite proportion. This should be taken into account in interpreting results with low kaolin proportions in the presence of chlorite.

Relative percentages using peak heights were calculated by assuming an equivalence in concentration, if the intensities of $7 \AA$ kaolinite, $10 \AA$ illite-muscovite, $14 \AA$ chlorite, and $17 \AA$ montmorillonite, were in the ratio of $2: 1: 1: 4$. The kaolinite, illite, and montmorillonite equivalences are in common use. The chlorite to illite equivalence was obtained experimentally from calibration curves of Mg-chlorite and illite mixtures.

The CEC method of calculating relative percentages uses the same equivalence ratios of intensities as stated, but ignores the montmorillonite peak height. The CEC of the sample is divided between the constituent minerals by assuming a CEC for each mineral: 100 for montmorillonite, 20 for illite, 12 for kaolinite, and 10 for chlorite (units in $\mathrm{meq} / 100 \mathrm{~g}$ ). The relative concentration given by the peak height is used to determine the actual contribution of the minerals kaolinite, illite, and chlorite to the total CEC. The remainder is assigned to montmorillonite. The potassium content is used to check the proportion of illite-muscovite obtained by the methods. It aids in determining the presence of high-potassium mica in the $10 \AA$ fraction. Crystallinity of this fraction was measured as the width at half peak height minus the instrument factor.

\section{Comparison Between Different Methods}

The results obtained by X-ray diffraction show a general agreement between the fully treated clays on oriented mounts (Figure 1) and the decalcified random oriented mounts (Figure 2). The main difference appears to be in the Neogene calcareous ooze samples at Site 281 , where the proportion of montmorillonite and illite is quite different. Analysis of the glauconite sample (Core 13) on the oriented mount showed an excellent symmetrical $10 \AA$ peak with a CEC of 19.2 , whereas the DSDP analyses of random mounts indicate a mixedlayer illite-montmorillonite. Perhaps different samples were used for these analyses. The calcareous ooze above Core 13 at Site 281 contains scattered glauconite pellets, so that some of the illite in Figures 1 and 2 may represent authigenic glauconite.

The determination of montmorillonite by cation exchange method gave similar results to that obtained by X-ray diffraction, except for samples adjacent to the extrusive or intrusive basalts at Sites 280 and 282, the organic carbon-rich sediments in the lower part of Site 280, and the very well-crystalline montmorillonitic sediments at Site 283. In all these cases, the montmorillonite values determined by CEC were significantly lower than those determined by X-ray diffraction. These samples are being investigated further.

\section{RESULTS AND DISCUSSION}

Site 282 is closest to an Australian continental influence, and the dominant clays are montmorillonite and kaolinite. The increase in montmorillonite from late Eocene to middle Oligocene is accompanied by a decrease in kaolinite. Illite and muscovite have a fairly constant and low percentage (but high potassium content), and chlorite is present in trace amounts only. The limited early Miocene and Pleistocene results are similar to the above. Such an assemblage suggests a persisting supply from a deeply weathered landmass, with the increase of montmorillonite probably related to increasing volcanic activity from the Oligocene into the Miocene. This is observed in the volcanism of Tasmania (Sutherland et al., 1973). Some decrease in kaolinite suggests reduced weathering (colder) conditions on Tasmania and southeast Australia during the Oligocene.

Clay minerals at Sites 280, 281, and 283 are distinguished by the presence of significant amounts of chlorite, sometimes to the exclusion of kaolinite as at Site 280. A much higher illite-muscovite content is also present, some of which shows the good crystallinity of muscovite (low numbers in the I column of Figure 1). These observations suggest an Antarctic influence, especially at Site 280 . The potassium content of the illites below Core $280 \mathrm{~A}-11$ is very low, which suggests that these illites and a soil(?) chlorite was being derived from temperate Eocene conditions on Antarctica, without the intense leaching which was producing kaolinite in Australia at the same time. In contrast, the clays above Core 280 A-11 show a high potassium content $(8 \%-10 \% \mathrm{~K})$ indicating a muscovite-type mica. This, together with a high chlorite content, suggests cold to glacial conditions in the source area, here postulated as Antarctica. Clay minerals of Oligocene and Miocene sediments in the Australian and New Zealand sections of the ocean around Antarctica show surprisingly little variation with time and consist dominantly of mica and montmorillonite with a significant proportion of chlorite, but virtually no kaolinite (DSDP Leg 28, Sites 266 to 269, and 274). This suggests that the mica and chlorite may have been steadily supplied from the cold or glaciated Antarctic continent, and that this influence reached Site 280 which was quite close to that continent during the Oligocene.

The high Eocene montmorillonite content at Site 280 is associated with the highly organic, "euxinic" con- 
ditions at that site. The montmorillonite probably formed from alteration of volcanic material which was derived from the active spreading center that must have existed a short distance to the south. Perhaps some of this fine-grained material also found its way north into the Tasman Sea as recorded by the clays at Site 283. In general, however, montmorillonite does not show an increase towards the contact with the underlying oceanic basement. This would be expected from the proximity of the volcanically active spreading centers. Sediments from the nearby continents obviously dominate the clay mineral assemblages.

Tertiary sediments to the southwest of New Zealand (Site Report Chapters 277, 278, 279, this volume) are dominantly biogenic, with only a small clay mineral content. This consists of dominant montmorillonite and mica from the Paleocene onwards, with kaolinite and chlorite both present in small, but significant amounts only from the early Oligocene. The Paleocene-Eocene assemblage is difficult to explain, but the OligoceneMiocene clays appear to be thoroughly mixed Australian and Antarctic assemblages.

\section{CONCLUSIONS}

1. The clay mineral assemblage at Site 282 is characteristically Australian in type, and this assemblage persists from the late Eocene.

2. A significant increase in montmorillonite occurs in the Oligocene at Site 282 and is probably related to the increasing volcanism in the Tasmanian region (Sutherland et al., 1973).

3. The clay mineral assemblages at Sites 280,281 , and 283 are broadly similar. They are distinct from those at Site 282 and are probably related partly to an Antarctic source. The Antarctic influence is most noticeable at Site 280 , which must have been quite close to that continent during the Oligocene.

4. Sediments in cores below Core 280A-11 (before the late Eocene) indicate temperate conditions on Antarctica. Sediments of the Oligocene in cores of Hole 280A and in cores near Antarctica (DSDP Leg 28) indicate cold to glacial conditions.

5. The clay mineral data support the hypothesis that there was no deep oceanic connection between the basins on either side of the South Tasman Rise, that is, no circum-Antarctic current until probably the late Oligocene.

\section{ACKNOWLEDGMENTS}

The authors wish to thank the Division of Soils, C.S.I.R.O., Adelaide, for use of their analytical facilities.

\section{REFERENCES}

Biscaye, P. E., 1964. Distinction between kaolinite and chlorite in Recent sediments by X-ray diffraction: Am. Mineral., v. 49 , p. 1281.

Hashimoto, I. and Jackson, M. L., 1960. Rapid dissolution of allophane and kaolinite-halloysite after dehydration. In Swineford, A. (Ed.), Clays and clay minerals, 7th Proc.: London (Pergamon Press), p. 102-113.

Mehra, O. P. and Jackson, M. L., 1960. Iron oxide removal from soils and clays by a dithionate-citrate system buffered with sodium bicarbonate. In Swineford, A. (Ed.), Clays and clay minerals, 7th Proc.: London (Pergamon Press), p. $317-$ 327.

Pow-foong Fan and Rex, R. W., 1972. X-ray mineralogy studies-Leg 14. In Hayes, D. E., Pimm, H.C., et al., Initial Reports of the Deep Sea Drilling Project, Volume 14: Washington (U.S. Government Printing Office), p. 677.

Rex, R. W. and Murray, B., 1970. X-ray mineralogy studies, Leg 4. In Badev, R. G., Gerard, R. D., et al., Initial Reports of the Deep Sea Drilling Project, Volume 4: Washington (U.S. Government Printing Office), p. 745.

Schultz, L. G., 1960. Quantitative X-ray determination of some aluminous clay minerals in rocks. In Swineford, A. (Ed.), Clays and clay minerals, 5th Proc.: London (Pergamon Press), p. 216-224.

Sutherland, F. L., Green, D. C., and Wyatt, B. W., 1973. Age of the Great Lake basalts, Tasmania, in relation to Australia Cainozoic volcanism: J. Geol. Soc. Australia, v. 20 , p. 85 . 